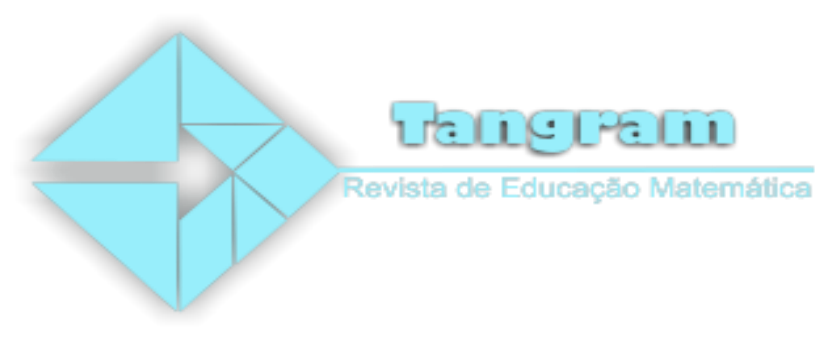

\title{
Educação Financeira para estudantes da Educação Superior
}

\section{Financial Education for students of Higher Education}

\author{
Francisca Tuanny Aparecida de Souza Silva ${ }^{1}$ \\ Aylla Gabriela Paiva de Araújo ${ }^{2}$ \\ Francisco Ronald Feitosa Moraes ${ }^{3}$ \\ Francisco Régis Vieira Alves ${ }^{4}$
}

\begin{abstract}
Resumo: Este trabalho aborda uma experiência com a Educação Financeira, objetivando apresentar os resultados das aplicações dos minicursos na modalidade de Ensino Superior, elaborados a partir de um projeto de extensão aprovado pelo edital 05/2017 da Pró-Reitoria de Extensão (PROEX) da Universidade Regional do Cariri, desenvolvido na Unidade de Campos Sales (URCA/UDCS), nos cursos de Ciências Biológicas, Letras e Matemática. Ocorreram quatro minicursos compostos por dois momentos, um teórico e outro prático. Para darmos início ao minicurso, aplicamos um questionário para identificar a média da idade dos participantes e como estavam sendo suas atitudes financeiras. Em seguida, foram explanados conteúdos de Educação Financeira e feitas atividades com os participantes para identificar situações de consumo consciente e compras por impulso. Durante a aplicação das atividades conseguimos observar nas discussões dos participantes um maior cuidado com seu orçamento e suas compras.
\end{abstract}

Palavras-chave: Educação Financeira; Minicursos; Compras;

Abstract: This paper approaches an experience with the Financial Education, aiming to present the results of the applications of mini-courses in the modality of Higher Education, elaborated starting

\footnotetext{
${ }^{1}$ Especialista em Ensino das Ciências da Natureza e Matemática pela Universidade Estadual Vale do Acaraú, UVA. Licenciada em Matemática pela Universidade Regional do Cariri, URCA. Licenciada em Ciências Biológicas pela Universidade Regional do Cariri, URCA. E-mail: tuanny.bio@ gmail.com

${ }^{2}$ Mestre em Ciências e Educação Matemática pela Universidade Estadual da Paraíba, UEPB. Graduada em Matemática pela Universidade Estadual da Paraíba, UEPB. Atualmente é professora assistente da Universidade Estadual do Rio Grande do Norte, UERN, campus Mossoró. E-mail: aylla_gabriela@hotmail.com

${ }^{3}$ Mestre em Educação pela Universidade Federal do Ceará, UFC. Especialista em Psicologia aplicada à Educação pela Universidade Regional do Cariri, URCA, Metodologia do Ensino de Matemática e Física pela Universidade Cândido Mendes, UCAM, e Gestão Escolar e Práticas Pedagógicas Universidade Cândido Mendes, UCAM. Licenciado em Matemática pela Universidade Regional do Cariri, URCA. Atualmente é professor Temporário de Educação Matemática no Curso de Licenciatura em Matemática da Universidade Regional do Cariri, URCA, campus Campos Sales.

${ }^{4}$ Doutor em Educação com ênfase no ensino de Matemática, pela Universidade Federal do Ceará, UFC. Mestre em Educação, com ênfase em Educação Matemática, pela Universidade Federal do Ceará, UFC. Mestre em Matemática Pura pela Universidade Federal do Ceará, UFC. Bacharel em Matemática pela Universidade Federal do Ceará, UFC. Licenciado em Matemática pela Universidade Federal do Ceará, UFC. Atualmente é professor do curso de Licenciatura em Matemática do Instituto Federal de Educação Tecnológica do Ceará, IFCE. E-mail: fregis@ifce.edu.br
}

Tangram - Revista de Educação Matemática, Dourados - MS - v.2 n. 2, pp. 16-27 (2019) 
to an extension project approved by the announcement $05 / 2017$ of the Pro-Rectory of Extension (PROEX) of the Regional University of Cariri, developed at the Campos Sales Unit (URCA / UDCS), in Biological Sciences, Letters and Mathematics courses. There were four mini-courses composed of two moments, one theoretical and the other practical. To start the mini-course, we applied a questionnaire to identify the participants' average age and how were being their financial attitudes. Then Financial Education contents were explained and activities were conducted with the participants to identify situations of conscious consumption and impulse shopping. During the application of the activities we got to observe in the participants' discussions a greater care with their budget and their shopping.

Keywords: Financial Education; Mini-courses; Shopping;

\section{Introdução}

Todas as pessoas necessitam de dinheiro para sobreviver, porém nossa cultura não ensina a planejar gastos ou pensar no futuro, consequentemente, temos um grande número de cidadãos, de diferentes níveis sociais, endividados e gastando mais do que ganham.

Hoje, a realidade dos jovens não é diferente, segundo uma pesquisa inédita feita pela Big Data da Serasa Experian, os jovens de 18 a 25 anos, representavam em março de 2016, $15,7 \%$ da inadimplência no país. Um fator preocupante, pois são cerca de 9,4 milhões de pessoas com dívidas atrasadas dentro desta faixa etária, ocupando o segundo lugar no ranking dos brasileiros negativados.

Com isso, nos questionamos: Como contribuir para divulgar a Educação Financeira na Educação Superior para diminuir as causas do alto índice de inadimplência dos jovens? Uma resposta possível para essa pergunta foi apresentar a Educação Financeira na Universidade para contribuir na formação financeira dos estudantes.

A Educação Financeira não se resume a aprender a economizar, cortar gastos, poupar e acumular dinheiro, vai além disso, proporciona melhorias na qualidade de vida tanto no presente quanto no futuro, proporcionando a segurança material necessária para usufruir dos prazeres da vida e ao mesmo tempo obter uma garantia para eventuais imprevistos.

Com isso, o presente artigo tem o objetivo apresentar os resultados das aplicações dos minicursos para a modalidade de Ensino Superior, do projeto de extensão intitulado "Educação Financeira para estudantes da Educação Básica e Superior", aprovado mediante seleção interna pela Pró-Reitoria de Extensão da Universidade Regional do Cariri e desenvolvido nas turmas dos Cursos de Licenciatura em Ciências Biológicas, Matemática e Letras da Unidade Descentralizada de Campo Sales (URCA/UDCS). 


\section{Educação financeira para estudantes da educação superior}

A primeira autora deste trabalho realizou a análise dos resultados, a segunda autora produziu a fundamentação teórica e procedimentos metodológicos e, o terceiro autor elaborou os resumos, as considerações finais e fez as correções no texto.

Os objetivos específicos dos minicursos foram: Compreender e divulgar a importância da Educação Financeira; Realizar minicursos sobre Educação Financeira relacionados ao cotidiano dos estudantes do Ensino Superior do curso de Biologia, Letras e Matemática; e, propor atividades utilizando situações de consumo consciente e compras por impulso.

Portanto, segundo a OCDE (2005), a educação financeira é definida como o processo pelo qual os consumidores melhoram o entendimento dos conceitos e riscos dos produtos financeiros, através de informações e instruções, que objetiva desenvolver habilidades de interpretar com mais consciência os ricos financeiros e as oportunidades que lhe são apresentadas e assim, fazer escolhas informadas e saber recorrer e tomar decisões que melhorem o bem-estar financeiro.

\section{A importância da Educação Financeira no Ensino Superior}

Quando falamos sobre Educação Financeira na Universidade, é comum estudantes e professores confundirem-na com a Matemática Financeira, pois afirmam já ter conhecimento do assunto. Segundo Scolari, Grando e Marasini (2013) a Educação Financeira se refere à capacidade de planejar e tomar decisões, já a Matemática Financeira está, justamente, conectada aos conceitos matemáticos, que também se apresentam como um grande desafio enfrentado pela população no mundo moderno.

Para Araújo (1992, p. 13), a "Matemática financeira é um ramo da Matemática Aplicada. Mais precisamente, é aquele ramo da Matemática que estuda o comportamento do dinheiro no tempo".

Essa falta de conhecimento da Matemática Financeira e Educação Financeira traz consequências para sociedade, pois os jovens estão cada vez mais endividados e uma dessas causas é a disponibilidade de crédito cada vez mais fácil e sem necessidade de comprovação de renda. Um caso corriqueiro é quando o aluno ingressa na Universidade e os bancos já oferecem cartões de créditos para os universitários.

Os projetos sobre a Educação financeira são recentes no Brasil, porém é um fator preocupante, pois, "a atitude da OCDE de incluir os bancos no processo de ensino da Tangram - Revista de Educação Matemática, Dourados - MS - v.2 n. 3, pp. 16-27 (2019) 


\section{Educação financeira para estudantes da educação superior}

Educação Financeira” (CAMPOS, 2013, p.15). Pois, seus objetivos estão mascarados, assim como afirma Britto (2012, p.33),

As instituições financeiras e bancárias são aquelas responsáveis em parcerias com o Estado, nas várias estratégias nacionais analisadas, de desenvolverem propostas curriculares de Educação Financeiras que, por sua vez, figuram como estratégias do capital, iniciativas neoliberais de produção/constituição de consumidores de produtos financeiros.

Por isso, devemos procurar meios e formas de incluir esse tema nas Universidades através de palestras, minicursos e até cursos à distância. AOCDE (2005) afirma que as pessoas devem ser educadas sobre questões financeiras o mais cedo possível em suas vidas.

Peretti (2008) alerta que educar financeiramente "é proporcionar uma mentalidade inteligente e saudável sobre dinheiro" (p. 06) e pode contribuir para o processo de formação de pessoas ativas e autônomas, que sejam capazes de tomarem decisões conscientes (PINHEIRO, 2015).

Os conteúdos relacionados entre a Matemática Financeira e a Educação Financeira são referentes ao sistema monetário, investimentos, porcentagem, lucro, desconto, juros, entre outros. Esses assuntos são propostos, desde a Educação Básica pelos Parâmetros Curriculares Nacionais (1998), para serem trabalhados com os alunos de forma que possam,

(...) compreender, avaliar e decidir sobre algumas situações da vida cotidiana, como qual a melhor forma de pagar uma compra, de escolher um financiamento etc. É necessário trabalhar situações-problema sobre a Matemática Comercial e Financeira, como calcular juros simples e compostos e dividir em partes proporcionais, pois os conteúdos necessários para resolver essas situações já estão incorporados nos blocos (Parâmetros Curriculares Nacionais, 1998, p. 86).

Porém, muitos alunos chegam a Universidade sem ter desenvolvido essas competências. Assim, acreditamos que é preciso desenvolver no aluno o senso crítico e reflexivo, fazendo com que ele pense quais os melhores cálculos e decisões a tomar e não fique apenas desenvolvendo repetitivas contas ou cursando disciplinas no Curso Superior com teorias e fórmulas prontas sem uma problematização.

Como afirma Kistemann (2011, p. 95) é importante

[...] não só desenvolver nos indivíduos-consumidores habilidades de cálculos matemáticos, estratégias formatadas de tomadas de decisão, mas, sobretudo, promover a participação crítica desses indivíduos nas mais variadas esferas de atuação social, refletindo sobre os panoramas financeiro-econômicos e produzindo significados que promovam o entendimento da Matemática, que permeia os lócus e as relações sociais e econômicas.

Tangram - Revista de Educação Matemática, Dourados - MS - v.2 n. 3, pp. 16-27 (2019) 


\section{Educação financeira para estudantes da educação superior}

Portanto, a realidade dos acontecimentos sociais e econômicos influencia nas tomadas de decisões dos jovens, e, por isso, eles precisam ter uma maior consciência no momento de administrar seu dinheiro.

\section{Metodologia}

O projeto de extensão "Educação Financeira para Estudantes da Educação Básica e Superior" teve uma duração de dois semestres durante o ano de 2017 e foi realizado na cidade de Campos Sales, Ceará.

No início do projeto selecionamos e preparamos dois bolsistas através de revisões bibliográficas e leitura do projeto para conhecimento e aprofundamento sobre os conceitos a serem utilizados nos minicursos.

Ainda na primeira etapa, os coordenadores junto aos bolsistas produziram os materiais das realizações dos minicursos e o questionário que abordava os dados pessoais, socioeconômicos dos participantes, além de questões sobre a Educação Financeira e seus hábitos de consumo.

$\mathrm{Na}$ segunda etapa, os orientadores e bolsistas entraram em contato com as coordenações dos cursos de Ciências Biológicas, Matemática e Letras da URCA/Campos Sales para apresentar a proposta e solicitar autorização para ministrar os minicursos de Educação Financeira.

Pensando na proposta das atividades, apresentamos um minicurso de duas horas com sugestões para uma vida financeira saudável, o qual foi ministrado inicialmente para um grupo de acadêmicos do curso de Matemática da URCA/Campos Sales. A primeira aplicação do minicurso serviu como diagnóstico para identificar o que seria necessário melhorar para a realização dos próximos minicursos.

Com isso, verificamos que duas horas eram insuficientes para o que pretendíamos apresentar e aumentamos o minicurso para quatro horas, nas quais conseguimos trabalhar utilizando atividades práticas.

Após todas as aplicações dos minicursos, a última fase da realização do projeto foi a produção acadêmica com os resultados adquiridos. A seguir apresentaremos a estrutura do Minicurso de Educação Financeira.

\section{Minicurso educação financeira no ensino superior}

Tangram - Revista de Educação Matemática, Dourados - MS - v.2 n. 3, pp. 16-27 (2019) 
O minicurso com a temática "Educação Financeira no Ensino Superior" teve um público alvo composto por jovens, discentes dos cursos da Universidade Regional do Cariri da Unidade Descentralizada de Campos Sales (URCA/UDCS).

A etapa inicial da aplicação constituiu-se de um questionário aplicado aos participantes dando sequência com a parte teórica, cada turma que participou do minicurso respondeu ao questionário que consistia em perguntas sobre seus dados pessoais e socioeconômicos, e a segunda parte sobre educação financeira e seus hábitos de consumo.

No momento teórico, abordamos noções básicas de educação financeira e sua importância, dicas de planejamento financeiro, como elaborar um orçamento doméstico, como classificar suas receitas e despesas, exemplos de usos de ferramentas que podem auxiliar na organização das finanças pessoais, noções de juros e como funcionam os regimes de capitalização, vantagens e desvantagens do crédito e seu uso consciente e diferença entre desejos e necessidades.

Apresentamos algumas ferramentas para facilitar a organização financeira como: Planilhas, Aplicativos de celular (Mobills; Moni; Finance; Orçamento Inteligente 2; Guia Bolso; Finance Plus), Softwares, Caderninho, Caderneta, entre outras. O intuito dessas ferramentas é guardar os registros de receitas e despesas em um lugar diferente de apenas a memória, evitando que haja o esquecimento de algum deles.

Já no momento prático, realizamos duas atividades envolvendo o consumo consciente e compras por impulsos, abordando uma situação de compras, relacionando teoria à prática, como apresentamos abaixo:

I. Atividade de consumo consciente e compras por impulso:

Solicitamos aos estudantes que observassem os consumidores em um momento cotidiano no supermercado e analisassem o comportamento de cada um deles. A seguir, deveriam classificar os comportamentos em compra "por razão" $(\mathbf{R})$ ou "por emoção" (E) de acordo com os itens abaixo relacionados:

1. Consumidora segurando dinheiro e analisando se é possível levar a segunda unidade de um produto que já está no carrinho. ( )

2. Consumidora com um skate no carrinho e olhando a Promoção deste produto: Compre 1 skate e leve a segunda unidade pela metade do preço. ( )

Tangram - Revista de Educação Matemática, Dourados - MS - v.2 n. 3, pp. 16-27 (2019) 
3. Consumidor comparando o produto que está na promoção com produtos concorrentes e opta por levar o produto que não está na promoção por se tratar de uma marca de referência e por ter lembrado-se da publicidade. ( )

4. Mãe explicando a filha que não se deve comprar um produto apenas por causa do personagem que está na embalagem. ( )

5. Consumidora triste com o carrinho muito cheio, inclusive com dois skates. ( )

6. Consumidor no caixa mostrando folheto de outro supermercado que tem produtos com preços mais baixos para requerer o desconto do anúncio do supermercado "PREÇO BAIXO" de que: cobre qualquer preço. ( )

7. Consumidor com listinha na mão. ( )

8. Ao ver a promoção do sabão em pó "preço baixo só hoje" a consumidora (que está sem carrinho e sem cestinha), lembra-se que está faltando sabão em pó na sua casa e por isso resolve levar uma unidade. ( )

FONTE: Curso Educação Financeira para Consumidores 2, da Escola Nacional de Defesa do Consumidor.

II. Atividade proposta no minicurso:

Suponha que seu salário líquido seja de $\mathrm{R} \$ 930,00$ reais. Porém, você tem que planejar seus gastos, pois nenhuma outra renda entrará durante o mês. Sabendo que seus gatos mensais estão descritos na tabela ao lado, faça uma lista de compras de uma cesta básica e vá as compras.

\begin{tabular}{|l|l|}
\hline Aluguel & $\mathrm{R} \$ 200,00$ \\
\hline Água e luz & $\mathrm{R} \$ 100,00$ \\
\hline Gás & $\mathrm{R} \$ 60,00$ \\
\hline Telefone & $\mathrm{R} \$ 30,00$ \\
\hline Gastos com transportes & $\mathrm{R} \$ 50,00$ \\
\hline Lazer & $\mathrm{R} \$ 100,00$ \\
\hline Gastos com medicamentos & $\mathrm{R} \$ 53,00$ \\
\hline Gastos supérfluos & $\mathrm{R} \$ 123,00$ \\
\hline
\end{tabular}

Tabela 1: Atividade do minicurso

Fonte: Autoria própria

Tangram - Revista de Educação Matemática, Dourados - MS - v.2 n. 3, pp. 16-27 (2019) 


\section{Educação financeira para estudantes da educação superior}

Após realizar as compras faça o cálculo para saber quanto custou sua cesta básica e analise se a receita está maior que as despesas.

O minicurso foi inicialmente ofertado para os alunos do curso de Matemática, mas no seu decorrer houveram alguns participantes de outros cursos e do Ensino Médio. A seguir, apresentaremos os resultados e análises obtidas dos questionários.

\section{Resultados e análise dos dados}

Os minicursos foram divulgados nas turmas do curso de Matemática e também por meio das redes sociais. Os horários e datas de realização das atividades foram estabelecidos conforme os horários que os bolsistas tinham disponibilidade durante a semana, o que dificultou a participação de algumas turmas que tinham aulas naqueles horários.

Foram formadas três turmas para as aplicações dos minicursos, onde o maior número de participantes foi do curso de Matemática. Um desses fatores foi o interesse pelo tema e disponibilidade de horários, além da divulgação com os grupos de Matemática.

Apresentaremos os resultados do questionário e alguns comentários das aplicações das atividades dos minicursos.

\section{Questionário}

Participaram dos minicursos um total de 58 estudantes, em sua maioria do curso de Matemática da Unidade Descentralizada da URCA de Campos Sales, foram 53 do referido curso, mais 3 discentes de outros cursos da URCA e 2 alunos do Ensino Médio. Num total de 33 do sexo feminino (57\%), 25 do sexo masculino (43\%).

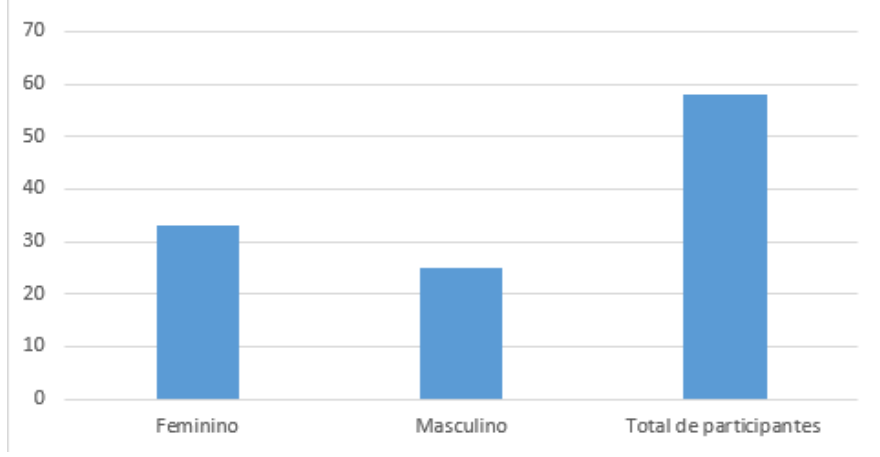

Gráfico 1: Participantes dos Minicursos

Fonte: Autoria própria

Tangram - Revista de Educação Matemática, Dourados - MS - v.2 n. 3, pp. 16-27 (2019) 


\section{Educação financeira para estudantes da educação superior}

A faixa etária foi bem diversa, com idades dos participantes variando entre 14 e 46 anos: $2 \%$ tinham de 14 a 16 anos; $34 \%$ de 17 a 19 anos; $43 \%$ de 20 a 22 anos; $12 \%$ de 23 a 25 anos; $5 \%$ de 26 a 28; $2 \%$ de 29 a 31 anos; e $2 \%$ de 44 a 46 anos.

Sobre a participação na vida econômica da família, 31\% dos participantes responderam que não trabalham e têm seus gastos custeados pelos familiares; 29\% que trabalham e são independentes financeiramente; 29\% trabalham, mas não são independentes financeiramente; e 11\% trabalham e são os principais responsáveis pelo sustento da família.

Em relação à quantidade de pessoas do núcleo familiar, na grande maioria (50\% dos casos) este núcleo possui entre cinco e oito pessoas; outros 36\% têm de duas a quatro pessoas; 7\% moram sozinhos; e 7\% têm núcleo familiar com nove ou mais indivíduos.

A renda familiar mensal de mais da metade dos participantes, $54 \%$ destes, é de menos de um salário mínimo, 34\% deles afirmaram que a renda familiar é de um a três salários mínimos e $12 \%$ disseram não ter nenhuma renda mensal.

Dos participantes, 34\% deles residem na cidade de Campos Sales, 29\% em Araripe, $28 \%$ em Salitre e $9 \%$ em outras localidades. A maior parte dos estudantes (60\%) reside na Zona Rural de seus municípios. 86\% deles moram em imóvel próprio, 9\% em casa alugada e $5 \%$ em casa cedida por terceiros.

Ao serem questionados se já ouviram falar em Educação Financeira, e se já participaram de algum curso ou aula sobre o tema, $19 \%$ deles já conheciam o tema e haviam participado de alguma palestra, aula ou curso sobre; $26 \%$ nunca tinham ouvido falar ou tido contato com este assunto; e grande parte deles (55\%) já havia ouvido falar sobre o tema, porém nunca participaram de nenhuma atividade relacionada a ele. O que mais uma vez demonstra a necessidade da abordagem e da promoção da educação financeira, seja com palestras, oficinas, ou aulas, as pessoas deveriam ter mais oportunidades e serem instigadas a se informar e discutir sobre o tema.

Quanto ao conceito de Educação Financeira, a maioria absoluta, 70\%dos que responderam ao questionário o resumem a "aprender a controlar os gastos e administrar bem o seu dinheiro", o que faz parte do contexto, mas acaba sendo uma definição muito simples. Apenas $10 \%$ dos cursistas associaram a educação financeira à mudança de hábitos e consumo consciente, $3 \%$ ainda confundiram com a disciplina de matemática financeira, relacionando-a com aprender a fazer cálculos específicos, e 17\% pessoas não souberam ou preferiram não responder.

Tangram - Revista de Educação Matemática, Dourados - MS - v.2 n. 3, pp. 16-27 (2019) 


\section{Educação financeira para estudantes da educação superior}

Sobre fazer o controle das suas finanças, $57 \%$ afirmaram que controlam suas receitas e despesas de alguma forma, seja fazendo anotações ou usando outras ferramentas. 7\% disseram que controlam eventualmente e $36 \%$ não têm o hábito de controlar seus gastos.

Ao serem questionados se tinham dívidas que não conseguiam pagar, 9\% não responderam, 29\% das pessoas têm ou conhecem alguém com dívidas e que não consegue pagar, os $62 \%$ restantes afirmaram não ter dívidas e não conhece alguém endividado.

\section{Aplicações das atividades dos minicursos}

A principal dificuldade encontrada durante as aplicações das atividades foi o tempo. A primeira tarefa, que envolvia identificar situações de consumo consciente e compras por impulso, os cursistas participaram com empolgação e conseguiram completá-la e debatê-la.

Passando para a segunda atividade, a das compras, a turma demorava muito na pesquisa de preços e organização da cesta básica. Acabávamos por encerrar o minicurso antes de a tarefa ser concluída, porém, ao analisarmos as discussões e o comportamento dos participantes durante a ação já foi possível perceber que eles estavam pondo em prática as dicas e conhecimentos adquiridos durante o minicurso.

No decorrer de todos os minicursos ministrados houve sempre uma grande participação e diálogo entre todos os envolvidos, o que tornou a atividade proveitosa e dinâmica e ajudou muito no andamento geral desta.

O minicurso contribuiu de fato para a formação profissional e universitária, pois todos os profissionais necessitavam aprender a administrar suas finanças, desde uma bolsa de estudo até seu salário. Assim, as atividades fizeram os participantes refletir sobre suas atitudes no momento de gastar seu dinheiro e assim, começar a corrigir seus erros e transformá-los em novas atitudes.

\section{Conclusão}

O projeto "Educação Financeira para Estudantes da Educação Básica e Superior” não se tratou de aprender conceitos, nem de cálculos ou fórmulas matemáticas, seu objetivo principal foi fazer com que as pessoas aprendessem a organizar sua vida financeira, tomando decisões sensatas e assim adquirindo uma boa qualidade de vida, planejando o seu futuro com maior tranquilidade.

Tangram - Revista de Educação Matemática, Dourados - MS - v.2 n. 3, pp. 16-27 (2019) 


\section{Educação financeira para estudantes da educação superior}

Com essa proposta aplicada sobre a Educação financeira alcançamos nos estudantes do Ensino Superior o entendimento sobre como é administrar seu dinheiro, analisar criticamente aspectos de negociações relacionados com a compra ou a venda de um determinado produto, verificando aspectos como qualidade e preço. Além, da percepção da existência de promoções e as propagandas enganosas, reforçando seus conhecimentos sobre a matemática básica financeira e, ensinando algumas habilidades de realização de investimentos e de gerir suas finanças.

Porém, não há nas instituições de ensino atividades ou políticas suficientes para que se promova a conscientização dos cidadãos sobre o uso responsável destes recursos que lhes são disponibilizados. O que contribui para a realidade do endividamento excessivo e da inadimplência, que atinge grande parte da população do nosso país, boa parte dessa formada por jovens, estudantes e universitários.

Concluímos que os participantes tiveram a oportunidade de conhecer diversas linhas de crédito (empréstimos, cartões de crédito, cheque especial) oferecido pelos bancos para que pudessem identificar se estas são boas alternativas de movimentação financeira, alertamos para a utilização dessas propostas de forma responsável e consciente. No qual acreditamos que contribuímos para uma orientação da estruturação financeira da vida profissional e pessoal de todos os participantes.

\section{REFERÊNCIAS}

Araújo, C. R. V. (1992). Matemática financeira: uso das minicalculadoras HP 12C e HP19BII. São Paulo: Atlas.

Parâmetros Curriculares Nacionais de 1998. (1998). Parâmetros Curriculares Nacionais: terceiro e quarto ciclos - apresentação dos temas transversais. Brasília: MEC/SEF, 1998.

Britto, R. R. (2012). Educação Financeira: Uma Pesquisa Documental Crítica. Dissertação de Mestrado. Universidade Federal de Juiz de Fora (UFJF), Juiz de Fora.

Campos, A. B. (2013). Investigando como a Educação Financeira Crítica pode contribuir para tomada de decisões de consumo de Jovens-Indivíduos-Consumidores (Jic's). Dissertação de Mestrado. Programa de Pós-Graduação em Educação Matemática, Universidade Federal de Juiz de Fora, Juiz de Fora, Minas Gerais.

Idec. (2008). Estudo sobre o crédito e superendividamento dos consumidores dos países do MERCOSUL. São Paulo. Recuperado em 06 de fevereiro, 2017, Tangram - Revista de Educação Matemática, Dourados - MS - v.2 n. 3, pp. 16-27 (2019) 
dehttp://www.senado.gov.br/noticias/jornal/cidadania/20100420/Relatorio_Idec_Superen d ividamento_CI_FINAL.pdf.

Kistemann JR., M. A. (2011). Sobre a produção de significados e a tomada de decisão de indivíduos-consumidores. Tese de Doutorado. Programa de Pós-graduação em Educação Matemática, Instituto de Geociências De Ciências Exatas, Campus de Rio Claro, Universidade Estadual Paulista, Rio Claro.

Peretti, L. C. (2008). Educação Financeira: aprenda a cuidar do seu dinheiro. Paraná: Instituto Stringhini Paraná.

Pinheiro, C. R. (2015). As contribuições do Programa Etnomatemática para o Ensino e Aprendizagem de Educação Financeira para alunos Surdos que se comunicam em Libras. EBRAPEM. Recuperado em 01 Março, 2017, de http://www.ufjf.br/ebrapem2015/files/2015/10/GD5_Rodrigo_Pinheiro.pdf

Serasa Experian. (2016). Inadimplência atinge 9,4 milhões de jovens no Brasil. $\begin{array}{lllll}\text { Recuperado em } & 27 & \text { Fevereiro, } & \text { 2017, }\end{array}$ http://noticias.serasaexperian.com.br/blog/2016/05/24/inadimplencia-atinge-94-milhoesde-jovens-no-brasil-revela-estudo-inedito-da-serasa-experian/.

Scolari, L. C., Grando, N. I; Marasini, S. M. (2013). Concepções de Professores de Matemática sobre Educação Financeira. VII CIBEM, Montevideo - Uruguai.

Enviado:30/09/2018 Aceito:10/04/2019

Tangram - Revista de Educação Matemática, Dourados - MS - v.2 n. 3, pp. 16-27 (2019) 